measurements of an increased flux of carbon dioxide, which escapes from magma while it is in the mantle at about $30 \mathrm{~km}$ depth, as well as inferences about the lava temperature and composition, indicate that the magma surge was sourced from the mantle.

The results indicate that after around 50 years of nearly uniform flow, the supply of magma from the mantle beneath Hawai'i changed over a timescale of just a few years. This observation is interesting in itself, but Poland et al. ${ }^{1}$ further illuminate some important consequences. A new eruption at the summit of Kilauea started in 2008 and is ongoing in 2012. The study shows that the volcano summit and the easternmost extent of the Kilauea rift zone $50 \mathrm{~km}$ away share a hydraulic connection. Thus, some of the magma flowing to the summit could move over large distances near populated areas. The entire volcanic system, including the Pu'u 'Ō'ō eruptive vent on the East Rift Zone, should therefore be monitored to mitigate the volcanic hazard. Furthermore, the neighbouring Mauna Loa volcano also experienced an injection of magma, the first in about 20 years, around May $2002^{8}$. Thus, there could also be some interconnection between Kīlauea and Mauna Loa, the two most active Hawaiian volcanoes in recent centuries.

It is unclear why the flux of magma from the Hawaiian hotspot to Kìlauea increased in 2003. Future work will search for detailed geochemical variations in the magmas $^{9}$ that could indicate whether the increased flux was due to a temporary change in the temperature or compositional structure of the mantle hotspot that is otherwise difficult to probe.

Importantly, the observed increase in carbon dioxide flux occurred about one year before the other manifestations of the increased magma flux, such as the increased emissions of sulphur dioxide, seismicity, surface deformation and lava temperatures. In the future, it is possible that measurements of carbon dioxide flux could be used as a predictive tool of changing magma flux and impending volcanic hazards.

Poland et al. ${ }^{1}$ show that Kìlauea Volcano experienced a sudden surge in magma supply after 50 years of almost constant flux. Kilauea has been continually erupting for almost 30 years and the characteristics of its eruption have changed frequently. These findings will inspire researchers, and possibly students, to investigate the beautiful and sometimes surprising behaviour of erupting volcanoes further - some of the data are available online in near-real time ${ }^{10}$.

Matthew Pritchard is in the Department of Earth and Atmospheric Sciences, Snee Hall, Cornell

University, Ithaca, New York 14850, USA. e-mail:pritchard@cornell.edu

References

1. Poland. M. P. et al. Nature Geoscience 5, 295-300 (2012).

2. Wolfe, C. J. et al. Science 326, 1388-1390 (2009).

3. Tilling, R. I. \& Dvorak, J. J. Nature 363, 125-133 (1993).

4. Delaney, P. T., Fiske, R. S., Miklius, A., Okamura, A. T. \& Sako, M. K. Science 247, 1311-1316 (1990).

5. Rhodes, J. M., Wenz, K. P., Neal, C. A., Sparks, J. W. \& Lockwood, J. P. Nature 337, 257-260 (1990).

6. Moore, J. P. Bull. Volcanol. 34, 562 (1970).

7. Sutton, A. J., Elias, T. \& Kauahikaua, J. in The Pu'u 'Ō'oKüpaianaha Eruption of Kilauea Volcano, Hawaii: The First 20 Years (eds Heliker, C. Swanson, D. A. \& Takahashi, T. J.) Ch. 8, 137-148 (Professional Paper 1676, US Geological Survey, 2003).

8. Miklius, A. \& Cervelli, P. Nature 421, 229 (2003).

9. Garcia, M. O., Pietruska, A. J. \& Rhodes, J. M. J. Petrol. 44, 2313-2339 (2003).

10. Poland, M. P., Kraft, K. \& Teasdale, R. Eos Trans. Am. Geophys. Union 92, 101 (2011)

11. Ryan, M. P. in Volcanism in Hawaii Vol. 2 (eds Decker, R. W., Wright, T. L. \& Stauffer, P. H.) Ch. 52 (Professional Paper 1350, US Geological Survey, 1987).

\title{
PALAEOCLIMATE
}

\section{Fossils from above}

Despite only faint light from the young Sun, the early Earth enjoyed fairly equable climates. These balmy temperatures could be explained by extremely high levels of carbon dioxide and other greenhouse gases. Measurements of carbon isotopes in 2.7-billion-year-old palaeosols,

however, suggest that the carbon dioxide concentrations would only have been high enough to maintain a temperate climate if the atmospheric nitrogen concentration was twice that of today's levels.

The nitrogen hypothesis is attractive, but without any measurements of atmospheric pressure during the Archaean eon, it remains speculative. Sanjoy Som of the University of Washington, Seattle, and colleagues (Nature http://dx.doi. org/10.1038/nature10890; 2012) propose that fossilized raindrop imprints allow a reconstruction of ancient atmospheric pressure from the rock record. They identified raindrop imprints in a layer of 2.7-billion-year-old volcanic tuff found near Prieska, South Africa.

The size of a raindrop is independent of atmospheric pressure. However,

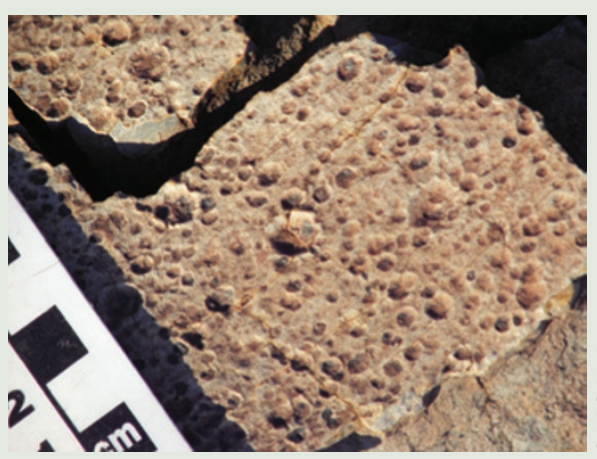

However, the most probable estimate for Archaean air density is less than $1.1 \mathrm{~kg} \mathrm{~m}^{-3}$, similar to modern values, a pressure that precludes a nitrogenenhanced efficacy of greenhouse gases. These atmospheric pressure values also rule out exceedingly high concentrations of carbon dioxide. There are, of course, other ways to explain Archaean warmth. A hazy atmosphere consisting of the greenhouse gas methane and fractal hydrocarbons would allow ammonia - a potent greenhouse gas - to persist in quantities sufficient to promote warming (Science

the terminal velocity of the raindrop is controlled by air density, and thus can provide bounds on atmospheric pressure. The team experimented on two different types of volcanic ash - the precursor to tuff - to identify the relationship between raindrop terminal velocity and the imprint left. Using the assumption that rain during the Archaean followed the same size distribution as modern rainfall, they find that the absolute upper limit of air density is $2.3 \mathrm{~kg} \mathrm{~m}^{-3}$, sufficient for the nitrogen hypothesis to be plausible.
$328,1266-1268 ; 2010)$. The search is on for other greenhouse gases that, although readily broken down in today's oxygenated atmosphere, may have been stable under more reducing conditions.

Identifying the components of the atmosphere billions of years ago is challenging, at best. And so it seems that despite decades of scientific effort, the faint young Sun paradox may remain just that for the foreseeable future.

ALICIA NEWTON 